\title{
Learning to Theorize in a Complex and Changing World
}

\author{
Hillary Swanson \\ Research Assistant Professor of Learning Sciences, School of Education and Social Policy, \\ hillary.swanson@northwestern.edu
}

\author{
Allan Collins \\ Professor Emeritus of Learning Sciences, a-collins@northwestern.edu \\ Northwestern University, 633 Clark St, Evanston, IL 60208, United States
}

\begin{abstract}
$\mathrm{T}$ o thrive in the modern world, people need to make sense of complex issues and deal with uncertainty. This requires a different kind of knowledge than schools are teaching. We argue that cultivating a theoretical turn-of-mind is critical for identifying causal relationships and patterns within any phenomenon and trend. In this paper, we introduce a course designed to engage students in an "intellectually honest" version of scientific theory building. We describe four theory-building competencies that students developed as a result of their participation in the course and highlight the features of instruction

that may have played a key role in this development. We describe how a particular feature of the course - the theorybuilding discussion - helped students refine their thinking and we outline the moves the teacher used to facilitate the refinement process. We conclude that learning to construct theories is beneficial even for students who are not tending towards careers in science, as it helps to refine everyday thinking, and, in a broader sense, build human capacities to develop solutions for the complex problems we face across economics, environment, health, and many other domains.
\end{abstract}

Keywords: theory building competencies; involvement of students; theoretical turn-of-mind; 21 st century skills
Citation: Swanson H., Collins A. (2019) Learning to Theorize in a Complex and Changing World. Foresight and STI Governance, vol. 13, no 2, pp. 98-106. DOI: 10.17323/2500-2597.2019.2.98.106 
$\mathrm{R}$ apid technological development changes every aspect of human activities and increases uncertainty. Efficient strategies in such context rely on non-standard solutions. Thriving in the $21^{\text {st }}$ century requires a different kind of knowledge than schools are teaching. Educators and policy makers need to understand how the world is changing and its implications for what students should learn. Routine jobs are disappearing as robots and computers become more sophisticated. Society and work are becoming ever more complex. If people are not educated to deal with this complexity, they will have a difficult time surviving in modern society. Schools everywhere are anchored in the past. They are teaching a curriculum that mostly dates several decades back. They simply are not preparing youth for the complexity of modern life.

In recent years governments around the world have invested extensive resources in preparing students for careers in science, technology, engineering, and mathematics (the so-called STEM disciplines), because they see them as critical for the future prosperity of their countries. They are the basis for most of the inventions and innovations that are critical to a growing economy. In simpler times before the industrial revolution, people did not need a deep understanding of mathematics and science to make intelligent decisions, but as the complexity of the world has increased, these skills have grown ever more important.

In his book Introduction to Mathematical Thinking, Keith Devlin [Devlin, 2012, p. 8] notes the two categories of mathematical skills important for a workforce advancing in an industrial society.

- The first category comprises people who, given a mathematical problem, can find its mathematical solution.

- The second category comprises people who can take a new problem, say in manufacturing, identify and describe key features of the problem mathematically, and use that mathematical description to analyze the problem in a precise fashion.

Devlin points out that, as routine work disappears, the need for people with mathematical skills of the first type is diminishing and the need for people with the second type is growing. Devlin's argument can be applied equally well to learning science. To thrive in the modern world of work, it is critical to be able to analyze problems, identify the elements and patterns comprising their deeper structure, and develop explanations for their causes in order to find workable solutions. These capacities are important aspects of scientific theory building. We therefore argue that it is critical for our students to develop theory-building skills.

Theory is central to science [Suppe, 1974, p. 3] and plays a powerful role in the development of technology [diSessa, 1991, p. 229]. Students should engage in theory building in order to learn elements of its associated practices and cultivate a theoretical turn-of-mind. Such engagement may also promote more nuanced perspectives on the nature of science and foster students' sense of epistemic agency. Despite its importance to science, theory building has been relatively underemphasized in the science classroom as compared with empirical investigation. Recently in the US, science educators have begun to focus on some aspects of theory building, such as modeling and explanation. However, these aspects do not capture the full range of theory-building practices.

To prepare our future scientists and foster the sensemaking skills necessary for all students to navigate the complex challenges of the $21^{\text {st }}$ century, educators need to articulate a broader category of theory-building practices and offer students opportunities to engage in them in meaningful ways in school. In this paper, we introduce a course that engaged students in an "intellectually honest" [Bruner, 1977] version of scientific theory building. We describe four theory-building competencies that students developed as a result of their participation in the course and highlight the features of instruction that may have played a key role in their development. We describe how a particular activity - the theory-building discussion - helped students refine their thinking and we outline the moves the teacher used to facilitate the refinement process. Finally, we consider the implications of our research findings for educating our future scientists and more broadly, citizens prepared to thrive in a complex and changing world.

\section{A Theory-Building Course}

According to Einstein, "The whole of science is nothing more than a refinement of everyday thinking" [Einstein, 1936]. This conveys the constructivist perspective on learning, where a learner builds formal knowledge by reorganizing and refining their prior knowledge [Smith et al., 1994]. The course was designed to help students refine their thinking through theory invention, test, and revision.

The course focused students on building theories about patterns in system behaviors (including threshold and equilibration) that can be seen in examples across domains, from physical to psychosocial. Threshold, for example, can be seen in the tipping point of a tower of blocks and the limit of a person's patience. Both phenomena exemplify a pattern of pre-phase, limit, and reaction, where a parameter is varied during a pre-phase until a limit is exceeded and the system reacts by making an irreversible transition to a new state. Equilibration can be seen in a glass of cold water warming to room temperature and the calming of a person's emotions. Both phenomena exemplify a pattern of difference drives rate where a system tends toward equilibrium quickly at first, and then more slowly as it approaches that state. Patterns like threshold and equilibration are concerned with the behavior underlying phenomena, or their deeper structure. Such patterns often capture causal relationships between events, and therefore have explanatory power. They are exemplified by many 
Table 1. The Framework of the Theory Building Course

\begin{tabular}{|l|l|l|}
\hline \multicolumn{1}{|c|}{ Unit } & Longevity (hours) & \multicolumn{1}{c|}{ Contents } \\
\hline Introductory & 6 & Introducing abstraction \\
\hline Threshold & 10 & Articulating deeper structure and determining a threshold pattern \\
\hline Equilibration & 20 & Articulating causal relationships and determining an equilibration pattern \\
\hline Practice & 16 & $\begin{array}{l}\text { Studying exponential growth and oscillation, practicing abstraction, articulating deeper } \\
\text { structure, and articulating causal relationships }\end{array}$ \\
\hline \multicolumn{2}{|l}{ Source: compiled by the authors. }
\end{tabular}

phenomena and are therefore best articulated in general terms, as abstract constructs.

These qualities make patterns a good target for theory building in the science classroom, as scientific theories are meant to convey the deeper structure underlying a class of phenomena [Toulmin, 1958; Hempel, 1974], to explain those phenomena [Hempel, Oppenheim, 1948], and to be abstract, so as to apply to a broad range of phenomena [Atkins, 2010]. Further, patterns can be explored through many different phenomena, so students can generate their own examples and construct their theories in contexts where they have some expertise. Though their pattern theories may vary in the degree to which they achieve deeper structure, explanatory power, and abstractness, all students can succeed at generating an initial theory, and all students can improve their theories by thinking about their own and their peers' ideas more carefully [Swanson, in press]. The theory-building course was tested and refined as part of a larger effort to understand middle school students' intuitions about patterns and how these intuitions could be leveraged by classroom instruction to help the students construct concepts of dynamical systems theory. Dynamical systems theory is a powerful framework used by scientists across domains to model processes of change and control [Devaney, 1992].

The course was implemented at a public middle school located in an economically depressed neighborhood of a large city in the western United States. The school was selected based on the willingness of the $8^{\text {th }}$ grade science teacher to share her elective class with our research team. The first author taught the course, having been a high school science teacher for six years before transitioning to research. She arranged to teach the course with the intention of explicitly cultivating a classroom culture that would support students in sharing, making sense of, and refining their everyday thinking. Twenty-one 8 th grade students (11 girls and 10 boys) participated in the course. Eighteen of the students had immigrated with their families to the US from Mexico and Central America. Two students identified as African American and one as Bosnian American. English was a second language for most students, Spanish being their primary language. The majority of students attending the school were designated as English Language Learners from low-income households. The students were selected on the basis of their availability and willingness to participate in the experimental curriculum.

The course staged the introduction of different tasks that comprised the pattern theory-building process. These included:

- describing the behavior underlying a single phenomenon (i.e., articulating deeper structure),

- explaining the cause of the behavior (i.e., articulating causal relationships), and

- generalizing the theory by articulating the elements of deeper structure common to multiple phenomena (i.e., abstraction).

The general framework of the course is presented in Table 1.

The course was implemented over an entire school year. The class met three mornings a week for 40 minutes, for a total of 52 hours of instruction. Students constructed theories of patterns exemplified by everyday phenomena, including patterns of threshold, equilibration, exponential growth, and oscillation. Pattern units were interspersed with lessons focused on how building pattern theories related to theory building in science.

For each unit, students individually constructed theories through an iterative cycle involving steps of generation, test, and refinement. They created a first draft of their theory after exploring two phenomena (provided by the teacher), which exemplified the pattern the teacher had in mind. They tested their nascent theory on a third example (also provided by the teacher) and then refined their ideas, producing a second draft of their theory. They generated a list of phenomena that exemplified the pattern and tested how well their theories fit these examples. They then refined their ideas, producing a third and final draft of their theory. Though the students were encouraged to build theories for the patterns that were salient to them, they were nudged in the direction of canonical conceptualizations of threshold, equilibration, exponential growth, and oscillation, as these were powerful for understanding concepts in dynamical systems theory. The teacher accomplished this by selecting particular exemplars and bringing the students' attention to productive ideas that were shared by students during class discussions. 
Students wrote their theories individually but were encouraged to share their ideas with their classmates. In all cases where students generated theories, they first worked alone and then shared their ideas once they had produced a draft. This was to create a space where students could carefully consider their own ideas and articulate them before exposing them to the critical review of their classmates. The 21 students were distributed across six tables and were randomly assigned their seats at the beginning of each month. When they investigated examples, they worked with one of their tablemates (except for a group of three, which worked together). When they created group artifacts such as posters, they worked with all students at their table.

\section{Introducing Abstraction}

Students were introduced to abstraction in an introductory unit. They were first introduced to the words general and specific. Students then practiced abstraction by creating and refining definitions for a general category that included chocolate chip cookies, oatmeal raisin cookies, graham crackers, Oreos, and other "objects" of the students' choice. The teacher led students in reflecting on their process with the intention of helping them see where they were engaged in abstraction (although they were never introduced to this term) by describing general features that were common to many specific examples.

\section{Introducing Deeper Structure}

Students were introduced to describing deeper structure in the context of a unit on threshold. A canonical conceptualization of threshold (as a pattern of prephase, limit, and reaction) guided the teacher's selection of exemplars. The unit guided students through the exploration of exemplary phenomena and the generation, test, and refinement of their own descriptions of the pattern they found across examples.

The unit opened with investigations of two threshold exemplars. The first was a challenge to see who could hang the most pennies from a spaghetti bridge. The second was a challenge to balance the greatest number of water droplets on a coin. The two examples were meant to complement each other because both examples featured coins. This similarity could illuminate whether students attended to common deeper structure or surface features and illustrate that what was meant by "pattern" was behavior common to both examples, rather than similarities in the objects they featured (such as coins). For both challenges, the students individually wrote descriptions and drew pictures of the behavior they had observed.

Following their exploration of the two examples, the students generated a first draft theory of the pattern they thought both examples followed. Their work was guided by the prompt: "Describe the pattern that the specific behaviors follow. One trick for doing this is to start by telling the story of both behaviors so that someone listening to your story would agree that you are talking about either one of the behaviors, but they wouldn't know for sure which one you were talking about." The prompt directed students to focus on the deeper structure behavior the examples had in common, as opposed to similarities in surface features. It also emphasized that the theory should be abstract, omitting the features that would tie it to either phenomenon.

Next, the students tested their theories against another exemplar: the addition of salt (one spoonful at a time) to a cup of water until a submerged egg floated to the water's surface. They were then invited to revise their thinking and write second drafts of their pattern theories. Following this, they generated their own list of pattern examples and then argued about whether or not these examples followed the pattern in the context of a whole-class debate. Following the debate, students were invited to revise their thinking a final time and write third drafts of their pattern theories.

\section{Introducing Causal Relationships}

Students were introduced to articulating a cause for a behavior in the context of a unit on a pattern of equilibration. This was a pattern of difference drives rate, where the rate of a system's equilibration is directly proportional to its distance from its equilibrium state. The unit followed the same basic structure as the threshold unit; however, a great deal of time was given to engaging students in crafting causal explanations for the behavior underlying each example.

The unit opened with investigations of two equilibration examples. The first investigation was on the rate at which a glass of cold water warmed to room temperature. The example illustrates difference drives rate because, when the temperature of the cold water is farthest from that of the room, the cold water warms fastest. This pattern is essentially Newton's law of heating. Students interpreted the data and noted that the temperature changed over time "fast and then slow." They individually generated explanations for this pattern and discussed their ideas in the context of a wholeclass theory-building discussion, which was meant to cultivate their capacity for articulating causal relationships in phenomena [Swanson, Collins, 2018].

The second example focused on the rate a glass of hot water cooled to room temperature and followed the same sequence as the cold water example. The students discussed the behavior exhibited by both cold and hot water examples and then generated initial theories for the pattern both examples followed. They wrote their theories in response to the same writing prompt as the threshold unit.

Next, they explored a third phenomenon that exemplified the pattern: particle diffusion. They simulated particle diffusion using a partitioned box that was filled on one side with two tablespoons of dried beans, shaking the box back and forth along the table so the beans moved in both directions through a small gap in the middle of the partition. In this example, the dif- 
Table 2. Aligning Students' Pattern Theories with Canonical Scientific Conceptualizations

\begin{tabular}{|l|l|}
\hline \multicolumn{1}{|c|}{ Unit } & \multicolumn{1}{c|}{ Canonical scientific conceptualization } \\
\hline Threshold & Pattern of pre-phase, limit, and reaction \\
\hline Equilibration & Difference drives rate \\
\hline Source: compiled by the authors.
\end{tabular}

ference between the number of beans on either side of the box drives the rate of the redistribution of beans. After recognizing the fast-and-then-slow pattern in the data, students wrote down causal explanations for the change in rate and then engaged in a brief theorybuilding discussion.

The students discussed how this example compared to the previous two examples and their previous pattern theories. They then wrote second drafts of their pattern theories. As in the threshold unit, they generated their own list of pattern examples and then argued about whether or not these examples followed the pattern in the context of a whole-class debate. They then wrote third drafts of their pattern theories.

We analyzed students' written theories and video footage of their class discussions using both qualitative and quantitative approaches. We found that students developed competencies for theory building and refined their everyday thinking to develop a deep scientific understanding [Swanson, in press]. We describe these findings and speculate on features of the course that may have fostered these learning outcomes.

\section{Cultivating a Theoretical Turn-of-Mind}

For both threshold and equilibration units, the students built abstract theories of the deeper pattern of behavior common to the examples they explored. Their work can be seen as existing on a continuum with the work of scientists. Below, we introduce four theory-building competencies the students demonstrated through their participation in the course. These are: 1) attention to empirical validity and completeness, 2) articulating deeper structure, 3) articulating causal relationships, and 4) abstraction. In our research, we found that participation in the theory-building course helped students develop these competencies and thereby cultivate a theoretical turn-of-mind [Swanson, in press].

\section{Attention to Empirical Validity and Completeness}

Scientific theories are evaluated with respect to their validity and completeness. We characterize the validity of a theory as the degree to which it corresponds with empirical observations [Wilensky, Rand, 2007], and its completeness as the extent to which it includes aspects that are consequential to explaining and predicting the phenomena to which it applies. In the patterns course, these competencies were operationalized together as the degree to which students' pattern theories aligned with canonical scientific conceptualizations (Table 2).

Our research showed that over the three drafts, students refined their everyday thinking into theories of threshold and equilibration that aligned better with the canonical scientific conceptualizations [Swanson, in press]. The key statistical data representing the evolution of learning process are reflected in Table 3.

The students gradually refined their ideas toward the scientific conceptualizations of threshold and equilibration through a process that was guided by the structure of the course. The main steps of process were having students articulate their ideas, consider one another's ideas, and engage in making sense of those ideas. Activities that elicited students' ideas included asking students to write down their pattern theory and share the pattern they had identified, or a possible causal explanation for a particular phenomenon. Activities that showcased ideas for students to consider included poster presentations, gallery walks [Kolodner, 2003], and writing ideas on the board. Activities that engaged students in making sense of one another's ideas included whole-class theory-building discussions and patternexample debates, during which the teacher asked students to evaluate, justify, challenge, or elaborate each other's ideas. For both pattern units, the refinement process moved back and forth between individual and group work, giving students time to think on their own and then engage in collaborative sense-making.

\section{Articulating a Deeper Structure}

Scientific theories are concerned with articulating the form of empirical regularities [Toulmin, 1958] and the processes that underlie them [Hempel, 1974]. These can be thought of as deeper structure. The ability to look beyond the surface features of a phenomenon and articulate deeper structure is a hallmark of expertise in science [Chi et al., 1981] and is fundamental to the

\section{Table 3. Evolution of the Students' Theories over the Course}

\begin{tabular}{|l|l|l|}
\hline \multicolumn{1}{|c|}{ Unit } & \multicolumn{1}{|c|}{ Initial formulations } & \multicolumn{1}{c|}{ Finite formulations } \\
\hline Threshold & $\begin{array}{l}\text { Over half of the students wrote theories } \\
\text { that focused on surface features or } \\
\text { included only one of the three elements - } \\
\text { pre-phase, limit, or reaction. }\end{array}$ & $\begin{array}{l}\text { Fifty percent had refined their theories to include all three elements of } \\
\text { pre-phase, limit, and reaction (e.g., "Repeating a process till something } \\
\text { happens"); } \\
\text { Thirty percent had refined their theories to include two of the three } \\
\text { elements (e.g., "Adding or taking something away till it reaches the } \\
\text { maximum"). }\end{array}$ \\
\hline Equilibration & $\begin{array}{l}\text { Over half of the students wrote theories } \\
\text { that focused solely on changing rate (e.g., } \\
\text { "The pattern went fast and then slow"). }\end{array}$ & $\begin{array}{l}\text { Sixty five percent had refined their theories to align with difference drives } \\
\text { rate (e.g., "There is a larger distance, so it goes fast. There is less space, so it } \\
\text { goes slow. No more space, so it stops."). }\end{array}$ \\
\hline \multicolumn{2}{|l}{ Source: compiled by the authors. }
\end{tabular}


construction of scientific theories. Deeper structure was operationalized in the context of students' pattern theories as a description of the behavior exemplified by a phenomenon (e.g., "Adding something to something until it changes"), as opposed to a description of its context-specific features (e.g., "Both used household objects"). The theory-building course guided students to look for the deeper dynamic interactions or relational structures [Gentner, 1983] exemplified by multiple phenomena, rather than similarities in their surface features.

Our research findings showed that, from the start of the threshold unit to the end of the equilibration unit, students improved their theories by removing surface features and shifting their focus to articulating the deeper pattern in behavior [Swanson, in press]. For example, at the beginning of the threshold unit, about three-quarters of the students described surface features the spaghetti bridge and drops-on-a-coin investigations had in common (e.g., "We used pennies in both of them"), and about three-quarters of the students included elements of deeper structure. ${ }^{1}$ By the end of the equilibration unit, all students' theories focused on deeper structure (e.g." "The space is greater at first, which makes it go fast, then it slows down as the amount of space decreases"), and only $10 \%$ referred to surface features.

For both threshold and equilibration units, students began by exploring two examples that were near analogies (i.e., threshold: adding objects to container objects until they broke; equilibration: warming and cooling liquids). They identified the pattern based on the first two examples and then tested their pattern theory on a third example, which was more analogically distant (i.e., threshold: adding salt to water until an egg floated; equilibration: particle diffusion across a semi-permeable boundary). It is possible that working with the near examples helped students identify the relational structure, that knowing this relational structure helped them see it in the third example and the later ones they invented. In her research on analogy, Gentner found that giving novices two closely related examples (examples that matched both in terms of relational structure and surface features) helped them identify relational structure in those examples. Novices were then more likely to notice the relational structure in a more distant example [Gentner, 1983]. Gentner gave the name progressive alignment to the process of helping students find relational structure in more distantly analogous examples by having them first identify the relational structure in near examples [Loewenstein, Gentner, 2001].

\section{Articulating Causal Relationships}

A chief application of scientific theory is the explanation of empirical phenomena [Hempel, Oppenheim, 1948]. A scientist must therefore be able to articulate causal relationships within a phenomenon that might explain it. For example, the modern, differential equation form of Newton's law of heating expresses the proportional relationship between an object's rate of temperature change and the difference between its temperature and that of its environment as $\mathrm{dT} / \mathrm{dt}=\mathrm{k}$ $\left(\mathrm{T}_{\text {env. }}-\mathrm{T}_{\text {obj. }}\right)$. Physicists regard the temperature difference on the right-hand-side of the equation as a "thermodynamic driving force" that influences the rate of temperature change on the left-hand-side of the equation [diSessa, 2014, p. 806]. We therefore consider this (and similar relationships captured by other abstract mathematical models) to be a scientifically legitimate form of causality. The theory-building course guided students to first describe the behavior they perceived in multiple phenomena and then conjecture the cause of that behavior.

Our research findings showed that students began to articulate causal relationships in their theories during the equilibration unit and that they improved with respect to this over its course [Swanson, in press]. All theories produced during the threshold unit focused on describing the pattern in behavior, as did all of the first draft equilibration theories. By the end of the equilibration unit, two-thirds of the theories sought to explain the cause of the pattern in behavior (e.g." "Fast because there is more space to cover and it slows down because every time less space is available and with less space it can slow down").

The feature of the course that supported students' development of this skill was the theory-building discussion [Swanson, Collins, 2018], during which the students worked collaboratively to build a causal explanation for a particular pattern phenomenon. Their first discussion focused on the first equilibration exemplar: a glass of cold water that warmed to room temperature "fast and then slow." They engaged in similar discussions for the second (hot tea cooling) and third (shaking beans-in-a-box) examples, as well. The theory-building discussion brought students' attention to the causal elements of the underlying relational structure of each example. According to Gentner and Colhoun [Gentner, Colhoun, 2010], looking for causal relationships is a natural tendency: "In analogical matching, people are not interested in isolated coincidental matches; rather, they seek causal and logical connections, which give analogy its inferential power." The theory-building discussion therefore supported students' natural tendency to look for causal relationships and build explanations.

\section{Abstraction}

The usefulness of a scientific theory, in part, depends on its range of applicability [Atkins, 2010]. For this reason, scientific theories are articulated in ways that render them general and more broadly applicable [Suppe, 1972; Toulmin, 1958]. Drawing on von Glasersfeld [von

${ }^{1}$ Theories could contain both surface features and elements of a deeper structure. 
Table 4. Pedagogical Moves Used within the Course

\begin{tabular}{|l|l|}
\hline \multicolumn{1}{|c|}{ Aim } & \multicolumn{1}{c|}{ Impacts } \\
\hline Eliciting student ideas & $\begin{array}{l}\text { Drawing out students' knowledge by asking them to articulate their ideas and unpack their reasoning. } \\
\text { Eliciting moves sparked creative thinking and guided students to generate the raw material they would } \\
\text { ultimately refine into more formal knowledge over the course of the discussion. }\end{array}$ \\
\hline Showcasing student ideas & $\begin{array}{l}\text { Creating shared artifacts on which the community could reflect and out of which they could refine their } \\
\text { shared explanation. Some of the moves created momentary artifacts (e.g., verbal restatements) while } \\
\text { others created more permanent artifacts (e.g., writing ideas on the board). }\end{array}$ \\
\hline $\begin{array}{l}\text { Engaging students in } \\
\text { making sense of ideas }\end{array}$ & $\begin{array}{l}\text { Helping students consider their classmates' ideas more carefully. These moves sometimes led to the } \\
\text { production of new ideas (by sparking creative thinking); however, their most important function was the } \\
\text { modification of existing ideas (by facilitating critical thinking). }\end{array}$ \\
\hline $\begin{array}{l}\text { Helping students locate } \\
\text { themselves within a } \\
\text { broader landscape }\end{array}$ & $\begin{array}{l}\text { Pointing out how their discussion built on prior lessons, and how it was building toward lesson goals. } \\
\text { These moves were meant to help students gain perspective on the dynamics of the discussion process } \\
\text { as opposed to the meaning of its content. Given that these moves illuminate the process of knowledge } \\
\text { construction, they are meant to promote a kind of metacognition. }\end{array}$ \\
\hline $\begin{array}{l}\text { Framing students as agents } \\
\text { of scientific knowledge } \\
\text { construction }\end{array}$ & $\begin{array}{l}\text { Encouraging students participation by elevating the status of their meaning-making activities and } \\
\text { respecting their ideas as valuable contributions to the process. These moves were also meant to give } \\
\text { students a sense for the theoretical half of the scientific enterprise, in particular the role of human } \\
\text { creativity in constructing and evaluating knowledge. }\end{array}$ \\
\hline $\begin{array}{l}\text { Fostering equitable } \\
\text { participation }\end{array}$ & $\begin{array}{l}\text { Cultivating an environment in which participation was expected, promoted, made safe, and supported by } \\
\text { both encouraging and corrective feedback. }\end{array}$ \\
\hline Source: compiled by the authors.
\end{tabular}

Glasersfeld, 1991], abstraction is a process of drawing out "general ideas from experience" and "substituting a kind of place-holder or variable for some of the properties in the sensory complex we have abstracted from our experiences of particular things." Evidence of abstraction is identified in students' theories as the use of general or context-free language (e.g., "Goes fast then slow, eventually stops"), as opposed to context-specific language (e.g., "Goes slow to reach maximum room temperature"). In the patterns course, students were encouraged to use general language so that their theories could be applied to phenomena across domains.

Our research showed that over the course of both units, students' theories became more abstract [Swanson, in press]. Students accomplished this by decreasing their use of specific language and by increasing their use of general language. This means that over time, fewer students described the pattern in the context of a particular phenomenon (e.g., "We used pennies, we put the pennies in a container, we counted, we did it again") and more students described the pattern without referencing any particular phenomenon (e.g., "In a large distance it goes fast then when the space gets smaller it goes slow. Then when there's no more space it stops.").

It is likely that their consideration of many different examples played a key role in helping students create general theories. As their theory had to expand to include more and more distant examples, elements of surface-features common to previous, near-analogy examples would have to be removed. This can be seen in threshold, where one student's initial pattern theory (that was general to the spaghetti bridge and drops-ona-coin example) had to be revised from containing a reaction of "destroyed" to one of "changed," in order to include the third example, where the egg is not destroyed but rather, floats. Gick and Holyoak (1983) called the process of abstracting a common "core idea" from multiple analogs "schema induction." They conjectured that schema induction involved "deleting the differences between the analogs while preserving their commonalities" [Gick, Holyoak, 1983, p. 8]. In their research, they found that subjects struggled to derive schemas given a single analog, but given two analogs, they succeeded.

\section{Refining Everyday Thinking}

Our research has shown that the course helped students refine their everyday thinking into more scientific thinking. One activity seems to have played a particularly important role in this development: the theory-building discussion [Swanson, Collins, 2018]. Students began one such discussion by investigating the rate of temperature change over time for a glass of cold water as it warmed to room temperature. They used computer software to collect data for temperature over time as ice water warmed to room temperature. Following the investigation, they interpreted the data and described the temperature change over time as "fast and then slow." They then individually generated explanations for this pattern. Their explanations served as the basis for a class-wide theory-building discussion, through which the teacher facilitated their collaborative refinement of a causal explanation for the pattern.

Students began the discussion with idiosyncratic ideas about the temperature of the water "slowing to a stop" like a runner slowing to avoid crashing into a wall, and the temperature increasing quickly at the start because it was far away from the wall and therefore safe to go fast. Gradually, through guided discussion, the teacher helped students refine their ideas into a difference drives rate explanation reflective of Newton's law of 
heating [Swanson, Collins, 2018]. In our analysis, we found that the teacher guided students' articulation and refinement of ideas through moves that elicited, showcased, and engaged students in making sense of their ideas. She facilitated the discussion more generally through moves meant to help students locate themselves within the broader landscape of their learning, to frame students as agents of scientific knowledge construction, and to foster equitable participation. The characteristics of the pedagogical moves are summarized at Table 4.

\section{Conclusion}

In this paper, we introduced a course designed to engage middle school students in an "intellectually honest" version of scientific theory building. We discussed four theory-building competencies that students developed as a result of their engagement in the course and considered the features of instruction that may have helped cultivate these competencies.

Our work demonstrates that students can engage in aspects of scientific theory building and that, with the support of instruction, they can develop skills for participating in the practice. These findings challenge commonly held assumptions about the developmental capacities of young learners regarding both the identification of deeper structure and abstraction [Chi et al., 1981; Larkin, 1983]. We have also shown that the theory-building process helps students develop a deep understanding of scientific content through a process that mirrors that of scientific knowledge construction. By eliciting students' ideas and engaging them in making sense of their own and their classmates' ideas, the theory-building approach guides students to refine their everyday thinking. Theory building offers a constructivist approach to classroom instruction that productively leverages the prior knowledge students bring to their learning.

We argue that theory building in the science classroom offers benefits beyond the development of skills and content knowledge. It exposes students to a more authentic version of science as it is practiced by professionals. This gives them a more nuanced perspective on the nature of science and a sense for the role of human creativity in the development of scientific knowledge. It paints the development of scientific knowledge as a constructive process, rather than a process of discovery. This dispels the authority of scientists and received scientific knowledge, giving students a sense of agency and opening the possibility that they might one day contribute to the broader scientific discourse.

It seems particularly important, in working with students from historically marginalized groups, to give them a sense that they can take part in creating and challenging scientific knowledge. Positioning students as creators and evaluators of scientific knowledge can create a more inclusive experience of science by broadening "the content and form of science knowledge valued and communicated through education" [Bang et al., 2012, p. 304]. By honoring the everyday thinking students bring to their learning [Warren et al., 2001] and challenging the authority of received scientific knowledge [Bang, Medin, 2010], the approach works toward the objectives, shared by many teachers, to cultivate classrooms that are more inclusive and equitable. Instruction that honors learners' individual ways of thinking invites diverse perspectives to the construction of scientific knowledge, promotes the heterogeneity of ideas, and cultivates a healthy ecosystem for science. As Feyerabend [Feyerabend, 1993, p. 24] said: "Proliferation of theories is beneficial for science, while uniformity impairs its critical power."

From a social perspective, helping students cultivate a theoretical turn-of-mind is crucial. Society is faced with many problems, such as obesity, pollution, economic bubbles, and technological addiction. These are challenging issues that must be addressed with a different kind of thinking than the thinking that created them. It is imperative for education to focus much more on teaching students how to think critically and make sense of the complex problems that arise in life [Collins, 2017]. Developing creative and sustainable solutions requires understanding the deeper patterns and causal relationships that underlie complex phenomena. By helping students cultivate a theoretical turn-of-mind, we can prepare them to address the challenges of our complex and changing world.

\section{References}

Atkins P. (2010) The laws of thermodynamics: A very short introduction, Oxford: OUP Oxford.

Bang M., Medin D. (2010) Cultural processes in science education: Supporting the navigation of multiple epistemologies. Science Education, vol. 94, no 6, pp. 1008-1026.

Bang M., Warren B., Rosebery A.S., Medin D. (2012) Desettling expectations in science education. Human Development, vol. 55, no 5-6, pp. 302-318.

Bruner J.S. (1977) The process of education, Cambridge, MA: Harvard University Press.

Chi M.T., Feltovich P.J., Glaser R. (1981) Categorization and representation of physics problems by experts and novices. Cognitive Science, vol. 5, no 2, pp. 121-152.

Collins A. (2017) What's worth teaching: Rethinking curriculum in the age of technology, New York: Teachers College Press.

Devaney R.L. (1992) A first course in chaotic dynamical system: Theory and experiment, Reading, MA: Addison-Wesley Publishing Co. 
Devlin K. (2012) Introduction to mathematical thinking, Palo Alto, CA: Keith Devlin.

diSessa A.A. (1991) If we want to get ahead, we should get some theories. Proceedings of the Thirteenth Annual Meeting of the North American Chapter of the International Group for the Psychology of Mathematics Education (ed. R.G. Underhill), vol. 1 (Plenary Lecture and Reaction), Blacksburg, VA: Virginia Tech, pp. 220 -239.

diSessa A.A. (2014) The construction of causal schemes: Learning mechanisms at the knowledge level. Cognitive Science, vol. 38, no 5, pp. 795-850.

Einstein A. (1936) Physics and Reality. Journal of the Franklin Institute, vol. 221, no 3, pp. 349-382.

Feyerabend P.K. (1993) Against Method, London: Verso.

Gentner D. (1983) Structure-mapping: A theoretical framework for analogy. Cognitive Science, vol. 7, no 2, pp. 155-170.

Gentner D., Colhoun J. (2010) Analogical processes in human thinking and learning. On Thinking: Vol. 2. Towards a Theory of Thinking (eds. A. von Muller, E. Poppel, B. Glatzeder, V. Goel, A. von Muller), Heidelberg; New York; Dordrecht; London: Springer, pp. 35-48.

Gick M.L., Holyoak K.J. (1983) Schema induction and analogical transfer. Cognitive Psychology, vol. 15, no 1, pp. 1-38.

Hempel C. (1974) Formulation and Formalization of Scientific Theories: A Summary-Abstract. The Structure of Scientific Theories (eds. T.S. Kuhn, F. Suppe), Chicago: University of Illinois Press, pp. 244-254.

Hempel C.G., Oppenheim P. (1948) Studies in the logic of explanation. Philosophy of Science, vol. 15, no 2, pp. 135-175.

Kolodner J.L., Camp P.J., Crismond D., Fasse B., Gray J., Holbrook J., Puntambekar S., Ryan M. (2003) Problem-based learning meets case-based reasoning in the middle-school classroom: Putting Learning by Design into practice. Journal of the Learning Sciences, vol. 12, no 4, pp. 495-547.

Larkin J.H. (1983) The role of problem representation in physics. Mental Models (eds. D. Gentner, A.L. Stevens), Hillsdale, NJ: Lawrence Erlbaum Associates, Inc., pp. 75-98.

Loewenstein J., Gentner D. (2001) Spatial mapping in preschoolers: Close comparisons facilitate far mappings. Journal of Cognition and Development, vol. 2, no 2, pp. 189-219.

Smith III J.P., diSessa A.A., Roschelle J. (1994) Misconceptions reconceived: A constructivist analysis of knowledge in transition. Journal of the Learning Sciences, vol. 3, no 2, pp. 115-163.

Suppe F. (1972) What's wrong with the received view on the structure of scientific theories? Philosophy of Science, vol. 39, no 1, pp. 1-19.

Suppe F. (1974) The search for philosophic understanding of scientific theories: Introduction. The structure of scientific theories (eds. T.S. Kuhn, F. Suppe), Chicago: University of Illinois Press, pp. 244-254.

Swanson H. (in press) Refining everyday thinking through scientific theory building. Deeper learning, communicative competence, and critical thinking: Innovative, research-based strategies for development in 21st century classrooms (ed. E. Manalo), Abingdon-on-Thames: Routledge (in press).

Swanson H., Collins A. (2018) How failure is productive in the creative process: Refining student explanations through theory-building discussion. Thinking Skills and Creativity (Advanced online publication). Available at: https://doi.org/10.1016/j.tsc.2018.03.005, accessed 04.02.2019.

Toulmin S.E. (1958) Introduction to the Philosophy of Science, Watford: William Brendan and Son.

von Glasersfeld E. (1991) Abstraction, re-presentation, and reflection: An interpretation of experience and Piaget's approach. Epistemological foundations of mathematical experience (ed. L. Steffe), New York: Springer, pp. 45-67.

Warren B., Ballenger C., Ogonowski M., Rosebery A.S., Hudicourt-Barnes J. (2001) Rethinking diversity in learning science: The logic of everyday sense-making. Journal of Research in Science Teaching: The Official Journal of the National Association for Research in Science Teaching, vol. 38, no 5, pp. 529-552.

Wilensky U., Rand W. (2007) Making models match: Replicating an agent-based model. Journal of Artificial Societies and Social Simulation, vol. 10, no 4, article 2. Available at: http://jasss.soc.surrey.ac.uk/10/4/2.html, accessed 04.02.2019. 